Розглянуто приклади застосування у метричному просторі та просторі з індеgбінітною метрикою універсального багатоточкового інваріанта (УБТ інваріанта), відомого як визначник Келі-Менгера для системи чотиръох точок. Показано, що такий інваріант задає метричну структуру евклідового та псевдоевклідового просторів розмірності $\mathrm{n}=2$. Для иих просторів також отримані й проаналізовані вирази для УБТ інваріантів, пов'язані із застосуванням відповідних псевдовідстаней. Запропонований підхід можливий $i$ y просторах з розмірністю $\mathrm{n}>2$.

Вступ. Нехай $\left\{P_{1}, P_{2}, \ldots P_{m}\right\}$ - сукупність $m$ довільно обраних точок (далі - система $\mathrm{m}$ точок) метричного простору $\mathrm{M}_{1}$ з множини всіх метричних просторів $\mathbf{M}\left(\mathbf{M}_{1} \in \mathbf{M}\right)$. Система точок $\left\{\mathbb{P}_{\mathrm{i}}\right\}_{i=1}^{m}$ характеризується набором відстаней $r=\left\{r_{i j}\right\}_{i, j=1}^{m}$, де $r_{i j}=\rho\left(P_{i}, P_{j}\right), i \neq j \quad\left(r_{i i}=0\right)$. Якщо відстані у будь-якій системі $\mathrm{m}$ точок пов'язані співвідношенням $\mathrm{V}_{\mathrm{m}}(\mathrm{r})=\mathrm{C}$, де $\mathrm{V}_{\mathrm{m}}(r)$ - функція багатьох змінних, що набувають значень $\left\{r_{i j}\right\}_{i, j=1}^{m}$, а C - довільна стала, то для простору $\mathrm{M}_{1}$ можна запровадити поняття універсального багатоточкового інваріанту (УБТ інваріанту).

Означення 1. Універсальним багатоточковим інваріантом порядку $\mathrm{m}$ метричного простору $\mathrm{M}_{1}$ називають фуннкиію $\mathrm{V}_{\mathrm{m}}(\mathrm{r})$ від набору відстаней $\mathrm{r}$ у системі $\mathrm{m}$ точок, визначену для множини всіх метричних просторів М, яка нетривіально залежить від своїх аргументів (тобто $\mathrm{V}_{\mathrm{m}}(\mathrm{r}) \not$ const ) $i$ задовольняя умову

де С - довілъна стала.

$$
\mathrm{V}_{\mathrm{m}}(\mathrm{r})=\mathrm{C}, \quad \forall\left\{\mathrm{P}_{\mathrm{i}}\right\}_{\mathrm{i}=1}^{\mathrm{m}} \subset \mathrm{M}_{1},
$$

Конкретні приклади та загальні властивості УБТ інваріантів розглянуті в праці [1], де встановлено, що іхній порядок обмежений умовою $\mathrm{m} \geq \mathrm{n}+2$, де $\mathrm{n}$ - розмірність простору. Співвідношення типу $\mathrm{V}_{\mathrm{m}}(\mathrm{r})=\mathrm{C}$ використовують у геометрії відстаней $[5,6]$.

Якщо геометрія простору відома, то можна поставити задачу пошуку відповідних УБТ інваріантів. Ця задача $є$ розв'язаною лише для окремих типів геометрії $[1,5]$. Але не менш цікава обернена задача: визначити й описати геометрію метричного простору за явним виглядом інваріанта $\mathrm{V}_{\mathrm{m}}(\mathrm{r})$. Вона розглянута лише для ріманівських просторів сталої кривини, відмінної від нуля [2]. Розглянемо її також і для плоского двовимірного простору, але за припущення, що його метрика може бути індефінітною (у цьому випадку $r_{\mathrm{ij}}^{2}$ набувають будь-яких значень з $\mathbf{R}$ ). Відповідно отримані нижче результати стосуватимуться евклідового та псевдоевклідового просторів [4] розмірності $\mathrm{n}=2$.

Поняття УБТ інваріанта для простору з індефінітною метрикою означимо так само, як і для простору $\mathrm{M}_{1}$.

Означення 2. Універсальним багатоточковим інваріантом порядку $\mathrm{m}$ простору з індефінітною метрикою $\mathrm{W}_{1}$ називають фбункиію $\mathrm{V}_{\mathrm{m}}(\mathrm{r})$ від

ISSN 1810-3022. Прикл. проблеми мех і мат. - 2018. - Вип. 16. - С. 50-57. 
Застосування універсальних багатоточкових інваріантів у евклідовому та псевдоевклідовому ... 51 набору відстаней $\mathrm{r}$ у системі $\mathrm{m}$ точок, визначену для множини всіх просторів з індефінітною метрикою $\mathbf{W}$, яка нетривіально залежить від своїх аргументів (тобто $\mathrm{V}_{\mathrm{m}}(\mathrm{r}) \not$ const) $i$ задовольняє умову

$$
\mathrm{V}_{\mathrm{m}}(\mathrm{r})=\mathrm{C}, \quad \forall\left\{\mathrm{P}_{\mathrm{i}}\right\}_{\mathrm{i}=1}^{\mathrm{m}} \subset \mathrm{W}_{1} .
$$

Варто наголосити, що попри зовнішню схожість двох означень відстані $r$ в означенні 2 не мають нічого спільного 3 відстанями у метричному просторі і можуть бути як дійсними, так і уявними. Детальніше відстані для обох просторів означимо трохи згодом за допомогою відповідних метричних аксіом.

Оберемо об'єктом дослідження УБТ інваріант $D_{4}^{2}(r)$, заданий для системи чотирьох точок двовимірного простору $(\mathrm{n}=2, \mathrm{~m}=4)$, який має вигляд визначника

$$
D_{4}^{2}(r) \equiv \operatorname{det}\left(\begin{array}{ll}
r_{i j}^{2} & 1 \\
1 & 0
\end{array}\right)_{i, j=1}^{4}=\left|\begin{array}{ccccc}
0 & r_{12}^{2} & r_{13}^{2} & r_{14}^{2} & 1 \\
r_{21}^{2} & 0 & r_{23}^{2} & r_{24}^{2} & 1 \\
r_{31}^{2} & r_{32}^{2} & 0 & r_{34}^{2} & 1 \\
r_{41}^{2} & r_{42}^{2} & r_{43}^{2} & 0 & 1 \\
1 & 1 & 1 & 1 & 0
\end{array}\right|=0
$$

Цей УБТ інваріант, відомий як визначник Келі-Менгера [5, 6], відповідає евклідовій площині, але його можна використовувати і за припущення, що метрика простору індефінітна. Потрібно визначити геометричні властивості простору, що випливають безпосередньо з виразу (1).

Інше питання, яке варто дослідити, стосується вигляду самих УБТ інваріантів. Якщо вимірювати відстані довжиною дуги кола, що з'єднує відповідні точки, то можна отримати зовсім інші вирази для УБТ інваріантів того ж простору. Така ситуація може призводити до проблеми хибних метричних співвідношень.

Мета дослідження - розглянути приклади застосування евклідівського УБТ інваріанта (1) для аналізу геометрії відповідного метричного простору та простору з індефінітною метрикою і показати, що інваріант (1) задає метричну структуру цих просторів, а також проаналізувати вирази для УБТ інваріантів, що виникають в результаті використання псевдовідстаней.

Спершу треба з'ясувати особливості застосування УБТ інваріантів у просторі з індефінітною метрикою. Після цього використаємо інваріант (1) для характеристики метричних властивостей евклідового та псевдоевклідового просторів. Враховуючи властивості кола, знайдемо вирази для УБТ інваріантів цих просторів, які пов'язують псевдовідстані.

1. Приклади застосування евклідівського УБТ інваріанта. Розглянемо двовимірний простір, в якому задано УБТ інваріант (1). Згідно з означенням 1 або 2 відстані $r$ у системі будь-яких чотирьох точок цього простору пов'язані співвідношенням (1). Крім того, значення відстаней $r_{i j}$ між будьякими точками метричного простору обмежені аксіомами метрики:

$$
r_{i j}=r_{j i}, \quad r_{i i}=0, r_{i j}>0, r_{i j} \leq r_{i k}+r_{k j},
$$

де $\mathrm{i} \neq \mathrm{j} \neq \mathrm{k} \neq \mathrm{i}, \mathrm{r}_{\mathrm{ij}} \in^{\circ}$. Подібні умови, що обмежують значення відстаней, можна записати і для простору з індефінітною метрикою:

$$
\begin{aligned}
& r_{i j}=r_{j i}, \quad r_{i j}=0, \quad r_{i j}=\left\{\begin{array}{cc}
\left|r_{i j}\right|, & r_{i j}^{2} \geq 0, \\
i\left|r_{i j}\right|, & r_{i j}^{2} \leq 0 ;
\end{array}\right. \\
& \left|r_{i j}\right| \geq\left|r_{i k}\right|+\left|r_{k j}\right|, \text { якщо } r_{i j}^{2} \geq r_{i k}^{2} \geq r_{k j}^{2} \geq 0 \text { або } r_{i j}^{2} \leq r_{i k}^{2} \leq r_{k j}^{2} \leq 0 ;
\end{aligned}
$$


де $\mathrm{i} \neq \mathrm{j} \neq \mathrm{k} \neq \mathrm{i}, \mathrm{r}_{\mathrm{ij}}^{2} \in{ }^{\circ}$. При цьому в обох випадках відстані між точками геодезійних утворюють лінійну шкалу вимірювання: $r_{13}=r_{12}+r_{23}$ для будьяких трьох точок геодезійної, пронумерованих у порядку іх розташування на ній.

Обмежувальні умови (2) та (3) виконуються, наприклад, у евклідовому та псевдоевклідовому просторах відповідно.

Формально інваріант (1) можна використовувати не лише для аналізу метричного простору. Але тоді «відстані» $r_{i j}$ будуть означені по-іншому, а результати істотно залежатимуть від набору прийнятих метричних аксіом. Тому, використовуючи співвідношення (1) для двох типів простору, слід враховувати відповідні ім властивості (2) та (3).

Розглянемо систему чотирьох довільно обраних точок $\left\{\mathrm{P}_{1}, \mathrm{P}_{2}, \mathrm{P}_{3}, \mathrm{P}_{4}\right\}$ (рис. 1) і запровадимо такі позначення для відстаней між ними:

$$
r_{12}=c, r_{13}=a, r_{14}=q, r_{23}=b, r_{24}=h, r_{34}=s \text {. }
$$

Перепишемо співвідношення (1) з урахуванням цих позначень:

$$
D_{4}^{2}(r) \equiv\left|\begin{array}{ccccc}
0 & c^{2} & a^{2} & q^{2} & 1 \\
c^{2} & 0 & b^{2} & h^{2} & 1 \\
a^{2} & b^{2} & 0 & s^{2} & 1 \\
q^{2} & h^{2} & s^{2} & 0 & 1 \\
1 & 1 & 1 & 1 & 0
\end{array}\right|=0
$$

де також враховано рівності $r_{\mathrm{ij}}=r_{\mathrm{ji}}$ та $r_{\mathrm{ii}}=0$. Якщо розкрити визначник, то взаємну залежність відстаней (4) (характерну для площини Евкліда $[3$, п.11.3]) можна подати рівнянням

$$
\begin{aligned}
& 2\left[a^{2} h^{2}\left(s^{2}+c^{2}+q^{2}+b^{2}-a^{2}-h^{2}\right)+s^{2} c^{2}\left(a^{2}+h^{2}+q^{2}+b^{2}-s^{2}-c^{2}\right)+\right. \\
& \left.+q^{2} b^{2}\left(s^{2}+c^{2}+a^{2}+h^{2}-q^{2}-b^{2}\right)-q^{2}\left(a^{2} s^{2}+c^{2} h^{2}\right)-b^{2}\left(h^{2} s^{2}+a^{2} c^{2}\right)\right]=0 .
\end{aligned}
$$
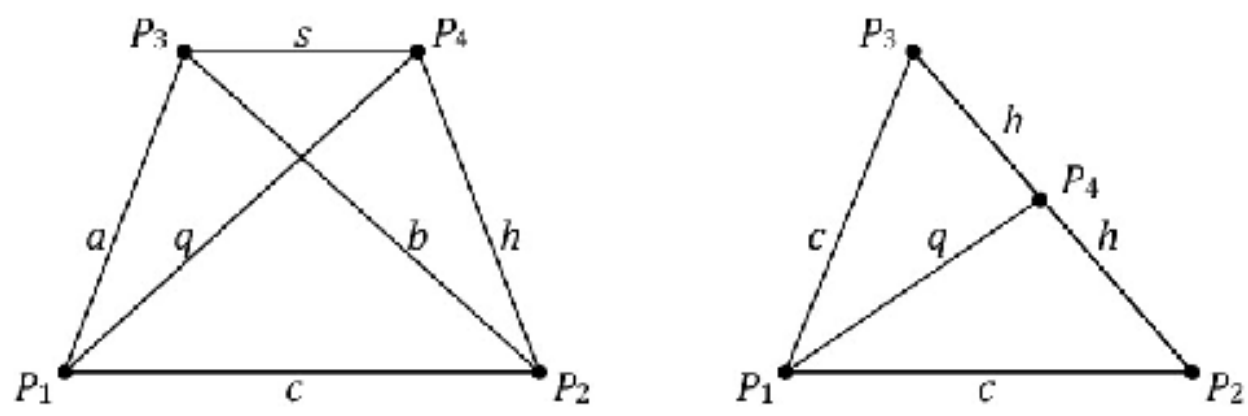

Рис. 1. Метричні співвідношення в системі чотирьох точок.

Розглянемо тепер деякі найважливіші приклади застосування інваріанта $D_{4}^{2}(r)$, використовуючи для цього вираз (4).

Приклад 1. Користуючись загальним рівнянням (4), можна легко знайти простіші метричні співвідношення, наприклад, співвідношення у прямокутному трикутнику або у паралелограмі. Якщо точка $\mathrm{P}_{4}$ лежить на відрізку геодезійної $\mathrm{P}_{2} \mathrm{P}_{3}$, тобто $\mathrm{b}=\mathrm{h}+\mathrm{s}, \mathrm{i}$ виконуються додаткові умови симетрії $\mathrm{s}=\mathrm{h}$ та $\mathrm{a}=\mathrm{c}$ (рис. 1), то отримаємо з рівняння (4) відомий вираз теореми Піфрагора:

$$
D_{4}^{2}(r)=-8 h^{2}\left(c^{2}-q^{2}-h^{2}\right)^{2}=0 \Rightarrow c^{2}=q^{2}+h^{2} .
$$


Застосування універсальних багатоточкових інваріантів у евклідовому та псевдоевклідовому ... 53

Для метричного простору з дійсними відстанями звідси випливає, що $\mathrm{c}>\mathrm{h}$ та $\mathrm{c}>\mathrm{q}$ для $\forall \mathrm{q}, \mathrm{h} \neq 0$. Якщо відстані можуть набувати уявних значень (індефінітна метрика), то одна з величин у правій частині (5) може бути уявною і цей вираз краще переписати так:

$$
c^{2}=|q|^{2}-|h|^{2}, \quad \text { де } q^{2}>0, h^{2}<0 .
$$

$\mathrm{y}$ просторі з властивостями (3) відстані $\mathrm{q}$ та $\mathrm{h}$ не можуть бути дійсними або уявними одночасно, оскільки в цьому разі $|c|^{2}=|q|^{2}+|h|^{2}<(|q|+|h|)^{2}$ i відповідно $|c|<|q|+|h|$, що суперечить умовам (3).

Приклад 2. Якщо в системі чотирьох точок виконуються умови $\mathrm{h}=\mathrm{a}$ та $b=q$, то маємо співвідношення

$$
D_{4}^{2}(r)=2\left(\left(q^{2}-a^{2}\right)^{2}-s^{2} c^{2}\right)\left(s^{2}+c^{2}-2 q^{2}-2 a^{2}\right)=0
$$

яке описує два випадки можливої реалізації вказаних умов - рівнобічну трапецію та паралелограм [3, п.11.2] з діагоналями q або S та С відповідно:

$$
q^{2}=a^{2}+s c \text { або } s^{2}+c^{2}=2\left(q^{2}+a^{2}\right) .
$$

$\mathrm{y}$ випадку паралелограма точки $\mathrm{P}_{2}$ та $\mathrm{P}_{4}$ на рис. 1 міняються місцями. Коли відстані S та C збігаються, отримуємо замість (7) співвідношення для прямокутника, еквівалентні виразу (5). У просторі з індефінітною метрикою діагоналі обох чотирикутників можуть дорівнювати нулю, а іхні сторони, згідно з (7), будуть тоді пов'язані лише між собою: $\mathrm{a}^{2}=-\mathrm{SC}$ (для трапеції) або $\mathrm{a}^{2}=-\mathrm{q}^{2}$ (для паралелограма).

Приклад 3. Нехай тепер точки $\left\{P_{1}, P_{2}, P_{3}\right\}$ лежать на колі з центром у точці $\mathrm{P}_{4}$. Тоді $\mathrm{q}=\mathrm{h}=\mathrm{s}=\mathrm{R}$, де $\mathrm{R}$ - радіус кола. Використовуючи знову співвідношення (4), знайдемо формулу для радіуса кола, описаного навколо трикутника зі сторонами $a, b, c$ :

$$
\begin{aligned}
& D_{4}^{2}(r)=2 R^{2}\left(2 a^{2} b^{2}+2 b^{2} c^{2}+2 c^{2} a^{2}-a^{4}-b^{4}-c^{4}\right)-2 a^{2} b^{2} c^{2}=0 \\
& \Rightarrow R=\frac{ \pm a b c}{\sqrt{(a+b+c)(b+c-a)(a+c-b)(a+b-c)}} .
\end{aligned}
$$

Отриманий результат збігається 3 відповідною формулою планіметрії $\mathrm{R}=\mathrm{abc} / 4 \mathrm{SV}$, якщо виразити площу трикутника SV через сторони $\mathrm{a}, \mathrm{b}, \mathrm{c}$ [3, п.3.3]. Згідно з вимогами аксіом метрики (2), всі відстані у формулі (8) дійсні, а підкореневий вираз більший від нуля (через нерівність трикутника). Тому для метричного простору треба обрати в чисельнику знак «+». Якщо метрика простору індефінітна і виконуються умови (3), то відстані a, b, с у (8) можуть бути дійсними або уявними лише одночасно (для забезпечення дійсності або уявності значення R ). Згідно з (3), незалежно від значень a,b,c підкореневий вираз завжди буде меншим від нуля внаслідок від'ємності одного зі співмножників (якщо всі співмножники відмінні від нуля). Тому для індефінітної метрики формулу (8) краще записати у вигляді

$$
R=\frac{a b c \cdot i}{\sqrt{|(a+b+c)(b+c-a)(a+c-b)(a+b-c)|}},
$$

де у чисельнику обраний знак «-» (щоб забезпечити невід'ємність R). Визначений за формулою (9) радіус буде уявним, якщо сторони трикутника дійсні, і дійсним, якщо вони уявні. 
У розглянутих випадках відомі формули евклідової та псевдоевклідової геометрії (5)-(9) отримані з виразу (4) для УБТ інваріанта $D_{4}^{2}(r)$. Так само можна одержати і складніші співвідношення, але для цього можуть знадобитись інваріанти вищого порядку [1].

Наступний приклад доводить застосовність УБТ інваріантів для опису координатного простору. Якщо відомо явний вигляд УБТ інваріанта, можна ввести в метричному просторі спеціальні координати, що збігаються з відстанями від $\mathrm{n}$ фріксованих точок. Такі координати утворюють у двовимірному просторі двополюсну систему радіальних координат ("bipolar coordinates" у [7, Гл.25]). 3 їхньою допомогою можна записати аналітичні рівняння окремих кривих і навіть визначити метрику і кривину, використовуючи для цього лише співвідношення типу $\mathrm{V}_{\mathrm{m}}(r)=\mathrm{C}$. До недоліків радіальних координат можна віднести неоднозначність визначеного ними положення, заданого одразу у двох напівпросторах.

Приклад 4. Розглядаючи дві пари відстаней $(\mathrm{a}, \mathrm{b})$ та (q,h) на рис. 1 як радіальні координати точок $\mathrm{P}_{3}$ та $\mathrm{P}_{4}$, можна знайти 3 рівняння (4) метричну фрункцію $\mathrm{s}=\mathrm{s}(\mathrm{a}, \mathrm{b}, \mathrm{q}, \mathrm{h})$ для відстані між двома довільними точками. Щоб обчислити відстань ds для пари сусідніх точок, покладемо $\mathrm{s}=\mathrm{ds}$, $q=a+d a$ та $h=b+d b$. Запишемо рівняння (4), зберігаючи лише члени найменшого порядку за ds, da та $\mathrm{db}$ :

$$
\begin{gathered}
D_{4}^{2}(r)=2 d s^{2}\left(2 c^{2} b^{2}+2 a^{2} b^{2}+2 a^{2} c^{2}-c^{4}-b^{4}-a^{4}\right)-8 a^{2} b^{2} d a^{2}- \\
-8 a^{2} b^{2} d b^{2}-8 a b\left(c^{2}-a^{2}-b^{2}\right) d a d b=0,
\end{gathered}
$$

де C - стала відстань між фріксованими точками $\mathrm{P}_{1}$ та $\mathrm{P}_{2}$. Розв'язуючи це рівняння відносно $\mathrm{ds}^{2}$, отримуємо такий вираз для метрики:

$$
d s^{2}=\frac{4 a^{2} b^{2} d a^{2}+4 a b\left(c^{2}-a^{2}-b^{2}\right) d a d b+4 a^{2} b^{2} d b^{2}}{2 c^{2}\left(a^{2}+b^{2}\right)-\left(a^{2}-b^{2}\right)^{2}-c^{4}}
$$

У метричному просторі також слід враховувати пов'язані з нерівністю трикутника обмеження $(\mathrm{a}+\mathrm{b} \geq \mathrm{c},|\mathrm{a}-\mathrm{b}| \leq \mathrm{c})$.

Квадратична фрорма цієї метрики означає, що відповідний простір описується в рамках ріманової геометрії. Це дає можливість за відомими фрормулами одразу знайти компоненти тензора кривини. Але тут для визначення геометрії простору достатньо перейти до прямокутних координат $\mathbf{x}$ та $\mathbf{y}$ :

$$
a^{2}=x^{2} \pm y^{2}, \quad b^{2}=(c-x)^{2} \pm y^{2},
$$

де знак «-» дозволяє врахувати можливу індефінітність квадрата відстані. Метрика (10) в цих координатах матиме вигляд

$$
d s^{2}=d x^{2} \pm d y^{2}
$$

Це доводить, що двовимірний простір з УБТ інваріантом (1) є евклідовим або псевдоевклідовим залежно від області значень $\mathrm{r}_{\mathrm{ij}}^{2}$.

2. Псевдовідстані та проблема вигляду УБТ інваріантів. Наведемо ще один приклад застосування радіальних координат $(a, b)$ і знайдемо довжину дуги кола. Нехай сусідні точки $\left(\mathrm{P}_{3}, \mathrm{P}_{4}\right)$ разом із точкою $\mathrm{P}_{1}$ лежать на колі з центром у точці $\mathrm{P}_{2}$ (рис. 2). Тоді $\mathrm{b}=\mathrm{c}=\mathrm{R}$, де $\mathrm{R}$ - радіус кола, який може набувати значень $\rho$ або i $\tau\left(\rho, \tau \in{ }^{\circ}>0\right)$ залежно від типу простору. Елемент довжини кола dl можна знайти з виразу для метрики (10), враховуючи, що для точок кола $\mathrm{db}=0$ : 


$$
\mathrm{dl}^{2}=\mathrm{ds}^{2}=\frac{4 \mathrm{R}^{2} \mathrm{da}^{2}}{4 \mathrm{R}^{2}-\mathrm{a}^{2}} \Rightarrow \mathrm{dl}=\frac{2 \mathrm{Rda}}{\sqrt{4 \mathrm{R}^{2}-\mathrm{a}^{2}}} .
$$

Проінтегруємо вираз (12) за дугою кола $\mathrm{C}_{10}$ від точки $\mathrm{P}_{1}(\mathrm{a}=0)$ до довільної точки $\mathrm{P}_{0} 3$ радіальною координатою $\mathrm{a}=\mathrm{r}_{10}=\mathrm{a}_{0}$. В евклідовому просторі $\mathrm{R}=\rho$ i довжина дуги

$$
\mathrm{I}_{10}=\int_{\mathrm{C}_{10}} \mathrm{dl}=\int_{0}^{\mathrm{a}_{0}} \frac{2 \rho d \mathrm{a}}{\sqrt{4 \rho^{2}-\mathrm{a}^{2}}}=2 \rho \cdot \arcsin \left(\frac{\mathrm{a}_{0}}{2 \rho}\right) .
$$

У псевдоевклідовому просторі радіус кола з дійсними відстанями між його точками буде уявним (згідно з (9)), тому, зберігаючи дійсні значення $\mathrm{a}, \mathrm{da}$ та $\mathrm{dl}$, треба обчислювати відповідну довжину дуги $\mathrm{l}_{10}$ за умови $\mathrm{R}=\mathrm{i} \tau$.
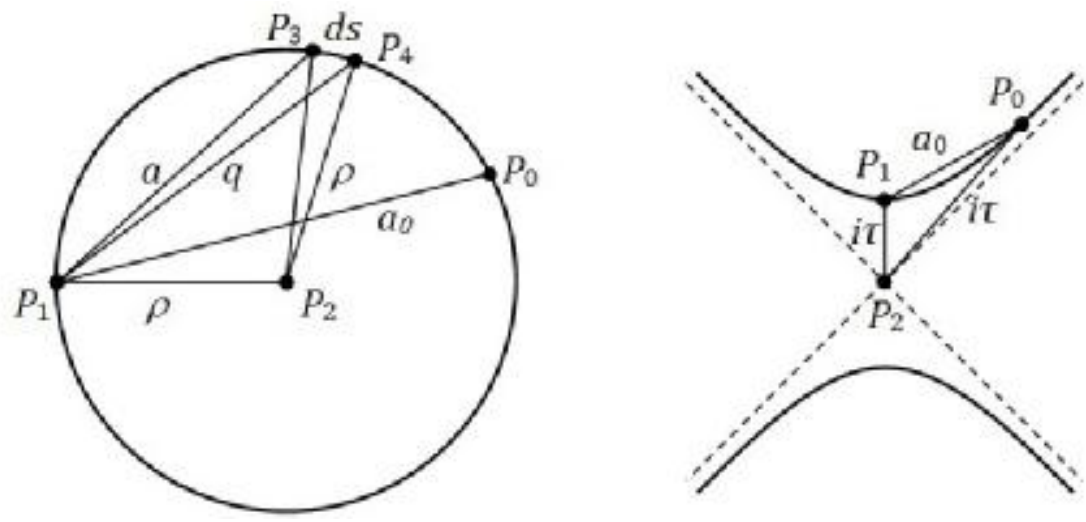

Рис. 2. Довжина дуги кола в евклідовому та псевдоевклідовому просторах.

3 виразу (13) випливає, що відстань $r_{i j}$ між двома довільними точками кола, які відтинають на ньому дугу довжиною $\mathrm{I}_{\mathrm{ij}}$, можна виразити через цю довжину за фрормулою

$$
r_{i j}=2 p \cdot \sin \left(\frac{l_{i j}}{2 p}\right) .
$$

У такий самий спосіб можна отримати відповідну формулу і для псевдоевклідового простору. Але простіше це зробити шляхом заміни $\rho \rightarrow \mathrm{i} \tau$ у формулі (14):

$$
r_{i j}=2 \tau \cdot \operatorname{sh}\left(\frac{I_{i j}}{2 \tau}\right) .
$$

Проаналізуємо отриманий результат. Вирази (14) та (15) не залежать від положення точок на колі або положення самого кола і тому встановлюють взаємно однозначну відповідність між величинами $r_{\mathrm{ij}}$ та $\mathrm{I}_{\mathrm{ij}}$. Це дає можливість, принаймні в окремих випадках, використовувати замість відстаней $r_{i j}$ відповідні ім довжини дуги $\mathrm{l}_{\mathrm{ij}}$ на колі радіусом $\rho$ або $\mathrm{i} \tau$. Крім того, якщо замінити відстані довжинами дуги кола, то для них так само існуватиме лінійна шкала вимірювання: для будь-яких трьох точок кола можна записати $\mathrm{I}_{13}=\mathrm{I}_{12}+\mathrm{I}_{23}$ (так само, як $\mathrm{i}$ для звичайних відстаней на прямій).

Водночас повноцінно замінити відстані $r_{i j}$ величинами $l_{i j}$ неможливо, оскільки вони не покривають всієї області значень $r_{i j}$. Відстані, визначені 
за формулами (14) та (15), будуть обмежені діаметром кола $\left(r_{i j} \leq 2 p\right)$ у евклідовому просторі або дійсними значеннями $\left(r_{i j}^{2} \geq 0\right)$ у псевдоевклідовому просторі відповідно. Таким чином, якщо вимірювати відстані між точками довжиною дуги кола, то такі псевдовідстані залишатимуться невизначеними тоді, коли відповідні значення $\mathrm{I}_{\mathrm{ij}}$ не існують.

Можливість використання псевдовідстаней $\mathrm{I}_{\mathrm{ij}}$ має певні наслідки для методу УБТ інваріантів, які слід враховувати, застосовуючи його для аналізу метричних властивостей простору. Розкриємо суть проблеми.

Підставивши вирази (14) та (15) у (1), отримаємо співвідношення, якими пов'язані псевдовідстані $\mathrm{I}_{\mathrm{ij}}$ у системі чотирьох точок в евклідовому та псевдоевклідовому просторах:

$$
\begin{aligned}
& D_{4}^{2}(l, \rho) \equiv \operatorname{det}\left(\begin{array}{cc}
\sin ^{2}\left(k l_{i j}\right) & 1 \\
1 & 0
\end{array}\right)_{i, j=1}^{4}=0, \\
& D_{4}^{2}(l, \tau) \equiv \operatorname{det}\left(\begin{array}{cc}
\operatorname{sh}^{2}\left(k l_{i j}\right) & 1 \\
1 & 0
\end{array}\right)_{i, j=1}^{4}=0,
\end{aligned}
$$

де $I_{i j}$ - довжина дуги кола радіуса $R$, що з'єднує точки $P_{i}$ та $P_{j}$, $\mathrm{k}=1 / 2|\mathrm{R}|$. Визначники (16) та (17) зберігають загальну структуру УБТ інваріанта (1) і пов'язують величини $\mathrm{I}_{\mathrm{ij}}$, які формально рівноцінні відстаням. Ці вирази виглядають як УБТ інваріанти, записані для того ж простору, що і (1), що ускладнюе ідентифікацію інваріанта $V_{m}(r)$, залежного від справжніх відстаней.

Оскільки елементи довжини $\mathrm{dl}_{\mathrm{ij}}$ та $\mathrm{dr}_{\mathrm{ij}}$ збігаються (для сусідніх точок $\left.r_{i j}=d r_{i j} \rightarrow 0, I_{i j}=d l_{i j} \rightarrow 0\right)$, то метрику, яка випливає з виразів (16) та (17), можна привести до вигляду (11). Але, в той же час, співвідношення для псевдовідстаней $\mathrm{I}_{\mathrm{ij}}$ будуть вже не такими, як у просторах із метрикою (11), бо замість (1) маємо для них рівняння (16) та (17). Тому, якщо не враховувати, що $\mathrm{l}_{\mathrm{ij}} \in$ довжиною дуги кола, то можна отримати хибні співвідношення для відстаней. Крім того, визначники (16) та (17) не можна застосовувати як повноцінні УБТ інваріанти. Оскільки довжини $\mathrm{I}_{\mathrm{ij}}$ визначені не для всіх пар точок простору, функції $D_{4}^{2}(I, \rho)$ та $D_{4}^{2}(I, \tau)$ не матимуть сенсу для відповідних систем точок. Оскільки ці фрункції отримані безпосередньо з УБТ інваріанта евклідового та псевдоевклідового просторів, ї можна використовувати в цих просторах так само, як і УБТ інваріанти для відстаней, але з урахуванням області визначення, обмеженої лише тими системами точок, для яких визначені псевдовідстані $\mathrm{I}_{\mathrm{ij}}$.

Висновок. Розглянуті приклади та одержані результати розкривають можливості застосування в геометрії універсальних багатоточкових інваріантів. Вони також засвідчують, що ці математичні об'єкти досить зручні та дієві під час аналізу властивостей простору та розв'язання різних геометричних задач і дають можливість поглянути на них під іншим кутом.

За допомогою УБТ інваріанта $D_{4}^{2}(r)$ (доповненого набором метричних аксіом) вдається описати найсуттєвіші властивості геометрії відповідного двовимірного простору й показати, що цей інваріант задає метричну структуру евклідової та псевдоевклідової площин. Крім того, знайдено вирази 
для УБТ інваріантів (16) та (17), пов'язані з використанням у цих просторах псевдовідстаней - довжин дуги кола сталого радіуса $\mathrm{R}$. Такий самий підхід можливий і у просторах розмірності $\mathrm{n}>2$.

Діючи за подібною схемою, можна досліджувати геометрію просторів 3 будь-якими іншими УБТ інваріантами, які можна знайти як функції $V_{m}(r)$ із заданими властивостями. Але при цьому треба враховувати, що кожний УБТ інваріант $V_{m}(r)$ може мати вигляд функції від псевдовідстаней $\mathrm{V}_{\mathrm{m}}(\mathrm{r}(\mathrm{l}))$.

1. Дзякович Д. О. Про симетрії універсальних багатоточкових інваріантів, що лежать в основі елементарних геометрій // Прикладні проблеми механіки і математики - 2015. - 13. - С. 195- 206.

2. Дзякович Д. О. Універсальні багатоточкові інваріанти та геометрія просторів сталої кривини // Прикладні проблеми механіки і математики - 2017. - 15. C. 42- 49 .

3. Понарин Я. П. Элементарная геометрия. Т.1: Планиметрия, преобразования плоскости. - Москва: Изд-во МЦНМО, 2004. - 312 с.

4. Розенбельд Б. А. Многомерные пространства. - Москва: Наука, 1966. - 648 с.

5. Blumenthal L. M. Theory and applications of distance geometry. - New York: Chelsea Publ. Co., 1970. - 347 p.

6. Liberti L., Lavor C., Maculan N., Mucherino A. Euclidean Distance Geometry and A pplications / / SIAM Review. - 2014. - 56, № 1. - P. 3- 69 (arXiv:1205.0349)

7. Lockwood E. H. A Book of Curves. - Cambridge: Cambridge Univ. Press, 1961. $199 \mathrm{p}$.

ПРИМЕНЕНИЕ УНИВЕРСАЛЬНЫХ МНОГОТОЧЕЧНЫХ ИНВАРИАНТОВ В ЕВКЛИДОВОМ И ПСЕВДОЕВКЛИДОВОМ ПРОСТРАНСТВАХ

Рассмотрены примеры применения в метрическом пространстве и пространстве с индеgбинтной метрикой универсального многоточечного инварианта (УМТ инварианта), известного как определитель Кэли-Менгера для системы четырёх точек. Показано, ито такой инвариант задаёт метрическую структуру евклидова и псевдоевклидова пространств размерности $\mathrm{n}=2$. Для этих пространств также получены и проанализированы выражения для УМТ инвариантов, связанные с применением соответствующих псевдорасстояний. Предложенный подход возможен и в пространствах с размерностью $\mathrm{n}>2$.

\section{APPLICATION OF UNIVERSAL MULTIPOINT INVARIANTS IN EUCLIDEAN AND PSEUDO-EUCLIDEAN SPACES}

Examples of application in a metric space and a space with indefinite metric of the universal multipoint invariant (UMP invariant) known as the Cayley-Menger determinant for the four points system are considered. Shown, that such an invariant determines the metric structure of the Euclidean and pseudo-Euclidean spaces of dimension $n=2$. For these spaces, expressions for UMP invariants associated with the use of appropriate pseudo distances are also obtained and analyzed. The proposed approach is possible also in spaces with dimension $n>2$.

Укр. науково-дослід. конструкторсько-технол.

ін-т еластомерних матеріалів і виробів, Дніпро

Одержано 